\title{
CRESCIMENTO DE MUDAS DE BARU EM SUBSTRATO ENRIQUECIDO COM NITROGÊNIO, FÓSFORO E POTÁSSIO
}

\author{
Christian Luis Ferreira Berti ${ }^{1}$, Takeshi Kamada ${ }^{2}$, Mariana Pina da Silva ${ }^{3}$, June Faria \\ Scherrer Menezes ${ }^{4}$, Ana Carolina Silva Oliveira ${ }^{5}$

\footnotetext{
${ }^{1}$ Professor de biologia do IF Goiano - Campus Avançado Catalão e bolsista DCR/FAPEG/CNPq, Catalão-GO, Brasil.

${ }^{2}$ Professor do Departamento de Agronomia da Universidade de Rio Verde, Rio Verde-GO, Brasil.

${ }^{3}$ Professor de Agronomia da Universidade Estadual de Goias- Campus de Ipameri, Ipameri-GO, Brasil.

${ }^{4}$ Professor do Departamento de Agronomia da Universidade de Rio Verde, Rio Verde-GO, Brasil.

${ }_{5}^{5}$ Discente do Curso de Agronomia da Universidade de Rio Verde, Rio Verde-GO, Brasil.
}

RESUMO: O baru (Dipteryx alata Vog.) é uma espécie nativa do cerrado que apresenta potencial para diversos usos, inclusive em programas de recuperação de áreas degradadas. Porém, pouco se conhece sobre seus aspectos silviculturais, principalmente suas exigências nutricionais. O objetivo com esta pesquisa foi avaliar o crescimento inicial de mudas de baru em substrato comercial enriquecido com nitrogênio, fósforo e potássio. $\mathrm{O}$ delineamento experimental utilizado foi o inteiramente casualizado, com cinco tratamentos e quatro repetições, sendo cada repetição representada por 12 mudas. Os tratamentos foram: controle (somente substrato comercial); adubação nitrogenada $\left(150 \mathrm{~g} \mathrm{~m}^{-3}\right.$ de $\mathrm{N}$ utilizando sulfato de amônio na semeadura $+1,0 \mathrm{~kg}$ de sulfato de amônio diluído em $100 \mathrm{~L}$ de água aplicado em cobertura); adubação fosfatada (300 $\mathrm{g} \mathrm{m}^{-3}$ de $\mathrm{P}_{2} \mathrm{O}_{5}$ utilizando superfosfato simples na semeadura); adubação potássica (100 $\mathrm{g} \mathrm{m}^{-3}$ de $\mathrm{K}_{2} \mathrm{O}$ utilizando cloreto de potássio na semeadura $+0,3 \mathrm{~kg}$ de cloreto de potássio diluído em $100 \mathrm{~L}$ de água aplicado em cobertura) e; completo (mistura contendo $\mathrm{N}_{2} \mathrm{P}_{2} \mathrm{O}_{5}$ e $\mathrm{K}_{2} \mathrm{O}$, sendo 150,300 e $100 \mathrm{~g} \mathrm{~m}^{-3}$, respectivamente, na semeadura, $+1,0 \mathrm{~kg}$ de sulfato de amônio e $0,3 \mathrm{~kg}$ de cloreto de potássio aplicados em cobertura). O substrato comercial utilizado foi composto por casca de pinus e fibra de coco. As avaliações morfológicas das mudas foram realizadas aos 100 dias após a semeadura e, verificou-se que, o crescimento das mudas de baru não foi alterado pela adição de nutrientes no substrato comercial. Com base nos resultados obtidos, conclui-se que as mudas de baru não apresentaram resposta à aplicação de N, P e K, demonstrando potencial para o plantio em solos com baixos teores desses nutrientes.

Palavras-chave: Dipteryx alata Vog. Cerrado. Nutrição mineral. Produção de mudas.

\section{GROWTH OF SEEDLINGS DIPTERYX ALATA (VOG) ON SUBSTRATE ENRICHED WITH NITROGEN, PHOSPHORUS AND POTASSIUM}

\begin{abstract}
Baru (Dipteryx alata Vog.) is a native species of cerrado that presents potential for several uses, including in programs for the recovery of degraded areas. However, little is known about its silvicultural aspects, especially its nutritional requirements. The objective of this research was to evaluate the initial growth of baru seedlings in commercial substrate
\end{abstract} Cultura Agronômica, Ilha Solteira, v.26, n.2, p.191-202, 2017 
enriched with nitrogen, phosphorus and potassium. The experimental design was a completely randomized design, with five treatments and four replications, with each replicate represented by 12 seedlings. The treatments were: control (commercial substrate only); Nitrogen fertilization $\left(150 \mathrm{~g} \mathrm{~m}^{-3}\right.$ of $\mathrm{N}$ using ammonium sulphate at sowing $+1.0 \mathrm{~kg}$ of ammonium sulphate diluted in $100 \mathrm{~L}$ of water applied in cover); Phosphate fertilization $\left(300 \mathrm{~g} \mathrm{~m}^{-3}\right.$ of $\mathrm{P}_{2} \mathrm{O}_{5}$ using single superphosphate at sowing); Potassium fertilization $\left(100 \mathrm{~g} \mathrm{~m}^{-3}\right.$ of $\mathrm{K}_{2} \mathrm{O}$ using potassium chloride at sowing $+0.3 \mathrm{~kg}$ of potassium chloride diluted in $100 \mathrm{~L}$ of applied water); (Mixture containing $\mathrm{N}, \mathrm{P}_{2} \mathrm{O}_{5}$ and $\mathrm{K}_{2} \mathrm{O}$, with 150, 300 and $100 \mathrm{~g} \mathrm{~m}^{-3}$, respectively, at sowing, $+1,0 \mathrm{~kg}$ of ammonium sulphate and $0,3 \mathrm{~kg}$ of potassium chloride applied as cover). The commercial substrate used was composed of pine bark and coconut fiber. The morphological evaluations of the seedlings were performed 100 days after sowing and, it was verified that, the growth of the baru seedlings was not altered by the addition of nutrients in the commercial substrate. Based on the results, it was concluded that the baru seedlings did not respond to the application of $\mathrm{N}, \mathrm{P}$ and $\mathrm{K}$, demonstrating potential for planting in soils with low nutrient content.

Key words: Baru. Cerrado. Mineral nutrition. Seedling production.

\section{INTRODUÇÃO}

Dipteryx alata, conhecida popularmente como baru, cumbaru e cumaru, é uma espécie arbórea da família Fabaceae e nativa do Cerrado. Possui alta taxa de germinação, rápido estabelecimento das mudas e múltiplos usos, a citar: arborização, forragem, madeireiro, alimentação animal e humana, dentre outros (SANO et al., 2004; SANO et al., 2006). Porém, o desmatamento ocorrido na região do Cerrado tem comprometido o seu ambiente nativo, reduzindo a quantidade de espécies e, consequentemente, de animais que consomem do fruto do baru. O que faz desta, uma espécie promissora e cujo cultivo deve ser incentivado no bioma de Cerrado. No entanto, para essa espécie, bem como para a grande maioria das espécies nativas do cerrado, pouco se conhece sobre suas exigências e requerimentos nutricionais.

Para que haja o cultivo da espécie, há primeiramente, que se conhecer seu processo produtivo. Segundo Gonçalves et al. (2000) a produção de mudas é uma das fases de maior importância nos projetos de revegetação, sejam para fins comerciais ou ambientais. Isso porque, mudas de boa qualidade, com nutrição e substratos adequados, asseguram a adaptação e o crescimento após o transplantio no campo.

Portanto, a composição do substrato, suas características químicas e físicas são fatores primordiais para a produção de mudas. No entanto, possivelmente, apenas o substrato não conseguirá disponibilizar os nutrientes necessários para o desenvolvimento inicial da espécie. Por isso, a adição de nutrientes, principalmente, nitrogênio, fósforo e potássio, têm despertado o interesse dos pesquisadores e, vários trabalhos foram conduzidos a fim de estabelecer a melhor forma de fertilização das espécies florestais (RIBEIRO et al., 2008; PAIVA et al., 2009; CRUZ et al., 2011a; CRUZ et al.,2011b; CRUZ et al., 2012; FEITOSA et al., 2011; 
CAIONE et al., 2012; REIS et al., 2012; COSTA FILHO et al., 2013; SILVA et al.,2013; DUTRA et al., 2015.; SOUSA et al.,2015; VIEIRA et al., 2015b; CAVALCANTE et al., 2016).

Esse enriquecimento se dá por conta das funções que esses elementos exercem no crescimento e no desenvolvimento das espécies vegetais.

$\mathrm{O}$ nitrogênio $(\mathrm{N})$ é o nutriente mais exigido entre todos os demais. Essa necessidade está relacionada com sua função estrutural no vegetal, pois faz parte de componentes da célula e participa de processos como absorção iônica, fotossíntese, respiração, multiplicação e diferenciação celular (MALAVOLTA, 2006).

O fósforo (P) também possui funções estruturais importantes ao desenvolvimento vegetal, participando da fotossíntese, respiração, divisão e crescimento celular e principalmente, no fornecimento de energia (ATP), o que resulta no maior crescimento e desenvolvimento inicial, principalmente do sistema radicular (VIEIRA et al., 2015a).

De acordo com Sousa e Lobato (2004), o P é um dos nutrientes que merecem mais atenção na produção agrícola, principalmente, quando em solos da Região do Cerrado, pois, nesse caso, a disponibilidade desse elemento, em condições naturais, é muito baixa. Portanto, a adubação fosfatada, é uma prática imprescindível nesses solos.

Diferentemente do $\mathrm{N}$ e do $\mathrm{P}$, o potássio $(\mathrm{K})$ não tem função estrutural, mas está associado a maior resistência das plantas quando submetidas a condições adversas, como baixa disponibilidade de água e temperaturas extremas, por conta de sua função na abertura e fechamento dos estômatos (MALAVOLTA et al., 1997).

No entanto, são raras as informações encontradas na literatura sobre a aplicação de nitrogênio, fósforo e potássio no crescimento inicial de mudas de baru. De forma geral, as diferentes espécies florestais nativas apresentam exigências nutricionais distintas e, como inexiste uma recomendação específica para cada espécie, a maioria das recomendações é baseada nas exigências do eucalipto, com algumas adaptações.

Considerando a escassez de informações sobre as exigências nutricionais de espécies florestais nativas e a necessidade de incentivar a produção de mudas de baru, objetivou-se com esta pesquisa, avaliar a adição de N, P e K ao substrato comercial no crescimento inicial de mudas de baru (Dipteryx alata Vog.).

\section{MATERIAL E MÉTODOS}

O experimento foi realizado no viveiro de mudas da Universidade de Rio Verde, localizado nas coordenadas $17^{\circ} 14^{\prime}$ '53', de latitude Sul e $50^{\circ} 55^{\prime} 14^{\prime \prime}$ de longitude Oeste, em altitude de $715 \mathrm{~m}$.

O delineamento experimental utilizado foi o inteiramente casualizados (DIC) com cinco tratamentos e quatro repetições, sendo cada repetição representada por 12 mudas. Os 
tratamentos foram constituídos da seguinte forma: controle (substrato comercial Bioplant $®$ ); adubação nitrogenada ( $150 \mathrm{~g} \mathrm{~m}^{-3}$ de $\mathrm{N}$ utilizando sulfato de amônio); adubação fosfatada (300 $\mathrm{g} \mathrm{m}^{-3}$ de $\mathrm{P}_{2} \mathrm{O}_{5}$ utilizando superfosfato simples); adubação potássica $\left(100 \mathrm{~g} \mathrm{~m}^{-3}\right.$ de $\mathrm{K}_{2} \mathrm{O}$ utilizando cloreto de potássio) e N-P-K (em doses de 150, 300 e $100 \mathrm{~g} \mathrm{~m}^{-3}$ de $\mathrm{N}, \mathrm{P}_{2} \mathrm{O}_{5}$ e $\mathrm{K}_{2} \mathrm{O}$, respectivamente).

As adubações foram realizadas no momento do preenchimento dos tubetes com substrato comercial.

As sementes de baru foram coletadas de árvores matrizes nativas, encontradas no município de Indiara-GO. Os frutos foram embalados em sacos de aniagem e armazenados em câmara fria a $10{ }^{\circ} \mathrm{C}$ até o início do experimento, quando, então, foram partidos para extração das sementes. Para a produção de mudas, duas sementes de baru foram colocadas em tubetes com capacidade para $250 \mathrm{~cm}^{3}$ contendo o substrato comercial Bioplant ${ }^{\circledR}$ (composto por casca de pinus, agentes agregantes, vermiculita, fibra de coco e complementos minerais), a uma profundidade de $1 \mathrm{~cm}$ e dispostos em bandejas, realizando nesse momento, as adubações.

Uma amostra do substrato foi retirada e analisada conforme métodos descritos pela Embrapa (1997), obtendo-se os seguintes resultados: $\mathrm{pH}\left(\mathrm{CaCl}_{2}\right)=5,0 ; \mathrm{Ca}=2,2 \mathrm{cmol}_{\mathrm{c}} \mathrm{dm}^{-3}$; $\mathrm{Mg}=1,2 \mathrm{cmol}_{\mathrm{c}} \mathrm{dm}^{-3} ; \mathrm{CTC}=8,7 \mathrm{cmol}_{\mathrm{c}} \mathrm{dm}^{-3}$ e $\mathrm{V} \%=58$.

As primeiras germinações ocorreram 16 dias após a semeadura e, transcorridos mais 15 dias, efetuou-se a repicagem das plântulas, retirando-se a de menor tamanho. Para a recomendação de adubação (fontes de adubos, doses, formas de aplicação e épocas de aplicação) seguiu-se as indicações preconizadas por Silva e Stein (2008), optando-se pela utilização de sulfato de amônio, superfosfato simples e cloreto de potássio como fontes de $\mathrm{N}$, $\mathrm{P}$ e K, respectivamente. As adubações nitrogenada e potássica foram realizadas de forma parcelada e, a adubação fosfatada em uma única dose no momento da semeadura.

As primeiras adubações de cobertura ocorreram 15 dias após germinação, seguindo as recomendações de Silva e Stein (2008). Nesse caso, os tratamentos contendo N e K receberam aplicação adicional em cobertura, utilizando-se, $1,0 \mathrm{~kg}$ de sulfato de amônio diluído em 100 litros de água e, 0,3 kg de cloreto de potássio diluído em 100 litros de água. Sendo que, ao tratamento completo aplicou-se sulfato de amônio e o cloreto de potássio, também na forma de solução. As aplicações se deram de forma alternada. Na primeira aplicação (15 dias após a germinação) foram aplicados o sulfato de amônio e o cloreto de potássio; sete dias depois, apenas o sulfato de amônio foi aplicado; na semana seguinte, foram aplicados o sulfato de amônio e o cloreto de potássio e, assim, sucessivamente.

As análises morfológicas das plantas foram realizadas aos 100 dias após a semeadura. Para isso, a altura da parte aérea (AP) foi determinada utilizando trena, sendo medida a partir da região do colo até a ponta da última folha; o diâmetro do coleto (DC) foi medido com o auxílio de paquímetro digital; para a contagem do número de folhas (NF) considerou-se todas as folhas desenvolvidas. Para a determinação da massa seca da parte aérea (MSA), da massa 
seca das raízes (MSR) e da massa seca total (MST), as plantas foram seccionadas em parte aérea e raízes, embaladas em sacos de papel kraft e levadas à estufa de circulação de ar forçada a $70^{\circ} \mathrm{C}$, até a obtenção do peso constante e, pesadas em balança de precisão.

As características morfológicas: relação altura da parte aérea/diâmetro do coleto (AP/DC), relação altura da parte aérea/massa seca da parte aérea (AP/MSA), relação massa seca da parte aérea/massa seca das raízes (MSA/MSR), relação massa seca das raízes/massa seca da parte aérea (MSR/MSA) foram obtidas através de cálculos. Assim como o Índice de Qualidade de Dickson, para o qual se utilizou a equação: IQD= MST/(AP/DC) + MSA/MSR) (DICKSON et al., 1960).

Os dados obtidos foram submetidos à análise de variância e, quando houve efeito significativo, aplicou-se teste de Tukey a 5\% de probabilidade utilizando o programa estatístico Sisvar (FERREIRA, 2011).

\section{RESULTADOS E DISCUSSÃO}

Destaca-se, pertinentemente, a dificuldade de encontrar trabalhos científicos que pudessem ser comparados com o trabalho em apreço, o que pode ser atribuído a pouca disseminação da espécie na comunidade científica. Dificultando, em alguns momentos, a discussão sobre o referido tema.

Avaliando as características morfológicas, aos 100 dias após a semeadura, observou-se que o enriquecimento do substrato comercial com N, P e K promoveu efeito significativo somente sobre o diâmetro do coleto das mudas de baru (Tabela 1).

Tabela 1. Altura da parte aérea (AP), diâmetro do coleto (DC), massa seca da parte aérea (MSA), massa seca das raízes (MSR), massa seca total (MST) e número de folhas (NF) de mudas de baru aos 100 dias após a semeadura, em resposta à adubação do substrato com $\mathrm{N}$, $\mathrm{P}$ e K

\begin{tabular}{lcccccc}
\hline & AP & DC & MSA & MSR & MST & \multirow{2}{*}{ NF } \\
\cline { 2 - 5 } Tratamentos & $\mathrm{cm}$ & $\mathrm{mm}$ & $\mathrm{g}$ & $\mathrm{g}$ & $\mathrm{g}$ & \\
\hline Controle & 22,48 & $5,37 \mathrm{ab}$ & 5,54 & 3,95 & 9,49 & 35,84 \\
Com N & 22,46 & $5,5 \mathrm{ab}$ & 5,28 & 3,56 & 8,84 & 35,79 \\
Com P & 21,8 & $5,04 \mathrm{~b}$ & 5,02 & 3,77 & 8,79 & 34,73 \\
Com K & 21,74 & $5,14 \mathrm{ab}$ & 4,97 & 3,72 & 8,69 & 33,42 \\
Com N-P-K & 21,92 & $5,67 \mathrm{a}$ & 5,37 & 3,43 & 8,8 & 35,71 \\
\hline Teste F & $0,375^{\text {ns }}$ & $3,357^{*}$ & $1.170^{\text {ns }}$ & $0,859^{\text {ns }}$ & $0,648^{\text {ns }}$ & $1.150^{\text {ns }}$ \\
CV $(\%)$ & 18,5 & 18 & 29,2 & 28,1 & 31 & 19,5 \\
\hline
\end{tabular}

$\mathrm{CV}=$ Coeficiente de variação. Médias seguidas por letras distintas, na coluna, diferem entre si, pelo teste de Tukey $(\mathrm{P}<0,05)$.

Para o crescimento em diâmetro de colo, o tratamento com N-P-K foi o que proporcionou a maior média (Tabela 1), atingindo $5,67 \mathrm{~mm}$; enquanto a menor média foi

Cultura Agronômica, Ilha Solteira, v.26, n.2, p.191-202, 2017 
observada no tratamento em que se adicionou apenas P. Nesse caso, um aumento de $11 \%$ com o tratamento N-P-K.

As plantas do tratamento controle não diferiram estatisticamente dos demais tratamentos podendo inferir que o adequado suprimento de nutrientes aliado às propriedades físicas que o substrato comercial proporcionou ao desenvolvimento inicial das plantas (TRAZZI, 2011), pode ter contribuído para o aumento do diâmetro de coleto das mudas.

As espécies florestais respondem de forma distinta à aplicação de adubo fosfatado.

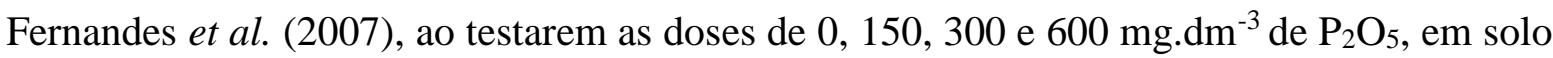
ácido, encontraram para mudas de Ceiba speciosa aos 180 dias de idade, maior produção de massa seca da parte aérea e de raízes na dose de $600 \mathrm{mg} \mathrm{dm}^{-3}$, enquanto que para Lithraea molleoides e Syzygium cumini não encontraram resposta à aplicação crescente de $\mathrm{P}$.

A falta de resposta para a adubação fosfatada pode ser justificada, uma vez que, o baru é pouco exigente quanto à fertilidade do solo (CARVALHO, 1994). De modo geral, as espécies pioneiras são mais exigentes nutricionalmente, mostrando-se bastante responsivas à fertilização, ao passo que, com o avanço do grupo sucessional o estímulo ao crescimento proporcionado pela adubação é menos pronunciado ou inexistente; tendência, em parte, atribuída ao crescimento mais lento (FURTINI NETO et al., 2005; SANTOS et al., 2008).

A literatura não apresenta parâmetros para avaliação do diâmetro e altura de mudas de baru. No entanto, ao comparar com as recomendações de Xavier et al. (2009) e Gonçalves et al. (2005), para os quais as mudas aptas ao plantio devem possuir entre 20 e $40 \mathrm{~cm}$ de altura e 2,0 mm de diâmetro, verifica-se que, as mudas de baru atingiram os valores em altura indicados. Sendo, no entanto, os valores obtidos de diâmetro de coleto de mudas de baru na presente pesquisa, superiores aos recomendados.

Isso é importante porque, segundo Souza et al. (2006) existe estreita correlação entre o diâmetro de coleto com a sobrevivência e com o ritmo de crescimento das mudas após o plantio no campo. Indicando que, quanto maior o diâmetro do coleto maior o desenvolvimento do sistema radicular e altura das mudas.

Esses resultados estão de acordo com os obtidos por Sgarbi et al. (1999), que verificaram que a eficiência das adubações depende basicamente das doses e fontes dos adubos utilizados, da capacidade de troca catiônica e das características físicas do substrato. Condições que foram encontradas, pelas mudas de baru, no substrato comercial utilizado.

Ressalta-se que, a altura de planta e diâmetro do colo são importantes parâmetros de análise morfológica, pois, plantas com deficiência de nutrientes apresentam desenvolvimento insatisfatório, afetando diretamente o seu crescimento. Além de serem os principais parâmetros analisados para a aquisição das mudas em viveiros. Portanto, essas características fornecem uma estimativa da predição do crescimento inicial no campo e são de fácil determinação (GOMES et al., 1991).

Cultura Agronômica, Ilha Solteira, v.26, n.2, p.191-202, 2017 
Outra característica morfológica que pode ser analisada é a produção de biomassa seca. Na produção de mudas, a biomassa seca é uma característica tão importante quanto a altura de plantas para classificar e quantificar o crescimento das mesmas no viveiro. No entanto, também não se observou diferença entre os tratamentos (Tabela 1) para a mesma, possivelmente devido aos resultados obtidos para altura e diâmetro, que estão relacionados à baixa exigência nutricional da espécie e aos nutrientes já existentes no substrato.

Não houve diferença significativa em relação ao número de folhas nas mudas de baru (Tabela 1), porém, destaca-se que, o maior crescimento foliar de mudas é desejável, já que as folhas realizam processos de conversão de energia luminosa em energia química (MARENCO e LOPES, 2005; TAIZ e ZEIGER, 2004), essencial para seu crescimento e desenvolvimento inicial.

Para os resultados referentes aos índices de qualidade das mudas, verificou-se diferença entre os tratamentos apenas para a relação entre a massa seca da parte aérea e massa seca das raízes (Tabela 2).

Tabela 2. Relação entre altura da parte aérea e diâmetro do coleto (AP/DC), altura da parte aérea e massa seca da parte aérea (AP/MSA), massa seca da parte aérea e massa seca das raízes (MSA/MSR), massa seca das raízes e massa seca da parte aérea (MSR/MSA) e Índice de Qualidade de Dickson (IQD) de mudas de baru aos 100 dias após a semeadura, em resposta à adubação do substrato com $\mathrm{N}, \mathrm{P}$ e K

\begin{tabular}{lccccc}
\hline \multicolumn{1}{c}{ Tratamentos } & AP/DC & AP/MSA & MSA/MSR & MSR/MAS & IQD \\
\hline Controle & 4,24 & 4,29 & $1,56 \mathrm{ab}$ & 0,72 & 1,72 \\
Com N & 4,20 & 4,39 & $1,67 \mathrm{ab}$ & 0,67 & 1,56 \\
Com P & 4,41 & 5,53 & $1,45 \mathrm{~b}$ & 0,75 & 1,55 \\
Com K & 4,27 & 4,63 & $1,44 \mathrm{~b}$ & 0,76 & 1,58 \\
Com N-P-K & 3,94 & 4,3 & 1,76 & 0,64 & 1,61 \\
\hline Teste F & $1.944^{\text {ns }}$ & $1.145^{\text {ns }}$ & $3.537^{* *}$ & $1.977^{\text {ns }}$ & $0.588^{\text {ns }}$ \\
CV $(\%)$ & 20,2 & 23,9 & 33,3 & 33,6 & 37,2 \\
\hline
\end{tabular}

$\mathrm{CV}=$ Coeficiente de variação. Médias seguidas por letras distintas, na coluna, diferem entre si, pelo teste de Tukey $(\mathrm{P}<0,05)$.

Os valores para a relação altura da parte aérea e diâmetro do coleto não apresentaram significância. No entanto, segundo Gomes et al. (2002), quanto menor for o valor dessa relação, melhor será a qualidade da muda, indicando um equilíbrio entre as partes da planta, o que pode resultar em maior resistência às condições adversas no campo impostas pelos fatores ambientais. Nesse caso, o menor valor foi verificado no tratamento N-P-K, que apresentou maior crescimento inicial das mudas. E, a não significância para esse valor está relacionada ao equilíbrio tanto no crescimento em altura quanto em diâmetro (BERNARDINO et al., 2005).

A relação entre altura da parte aérea e massa seca da parte aérea não é comumente usada como índice para avaliar o padrão de qualidade de mudas. Porém, com esta relação pode-se 
predizer o potencial de sobrevivência da muda no campo e, quanto menor for este índice mais lenhificada será a muda e maior será sua capacidade de sobrevivência no campo (GOMES e PAIVA, 2011). O que auxilia na explicação dos resultados obtidos com as mudas crescidas em substrato enriquecido com N-P-K.

A relação massa seca da parte aérea/massa seca das raízes foi influenciada pela adubação (Tabela 2), verificando-se que o tratamento com N-P-K, proporcionou a maior média. De acordo com Brissette (1984), mudas com valor igual a 2,0, seriam aquelas que apresentariam a melhor relação MSA/MSR, uma característica que explica a qualidade das mesmas para o transplantio. Enquanto, Caldeira et al. (2008) relataram que, essa relação deve ser de 2:1. No entanto, nenhum dos valores propostos pelas literaturas citadas foi observado no presente trabalho.

O índice de qualidade de Dickson (IDQ) é um indicador da qualidade das mudas, pois no cálculo são considerados, a robustez e o equilíbrio da distribuição da biomassa na muda, ponderando os resultados de vários parâmetros importantes empregados para a avaliação da qualidade (FONSECA et al., 2002). Nesse caso, quanto maior for o IQD, melhor será o padrão de qualidade da muda (GOMES; PAIVA, 2011; VIDAL et al., 2006).

Porém, Rossa et al. (2013), avaliando a qualidade de mudas de Schizolobium amazonicum produzidas em doses crescentes de adubo de liberação lenta, constataram que o IQD variou entre 0,29 e 0,58. Ainda segundo esses autores, mudas de qualidade devem ter, IQD maior ou igual a 0,20 , semelhante ao observado no presente trabalho.

Os resultados obtidos demonstraram que o baru, no início de seu crescimento, é pouco exigente em N, P e K. Isso se deve, provavelmente, ao tamanho da semente, ao alto teor de nutrientes presentes nela e, principalmente, à sua baixa exigência nutricional. O que torna a planta pouco dependente dos nutrientes do solo nesta fase, fato esse confirmado em experimento desenvolvido por Sousa et al. (2015). Segundo Furtini Neto et al. (2000), espécies que apresentam sementes com maior tamanho e peso, possuem maior conteúdo de compostos de reserva para atender à demanda por nutriente na etapa inicial de crescimento. Além disso, a espécie Dipteryx alata cresce pouco no primeiro ano, o que também pode contribuir para a pequena exigência nutricional nesta fase.

Portanto, as condições nutricionais do substrato comercial foram suficientes para manter o crescimento adequado das mudas até os 100 dias. Demonstrando que, a utilização do mesmo, na produção de mudas de espécies florestais deve ser precedida da análise nutricional do mesmo.

\section{CONCLUSÃO}

O crescimento das mudas de baru até os 100 dias não foi alterado pelo enriquecimento de N, P e K ao substrato comercial Bioplant ${ }$.

Cultura Agronômica, Ilha Solteira, v.26, n.2, p.191-202, 2017 


\section{AGRADECIMENTOS}

À Fundação de Amparo e Pesquisa do Estado de Goiás - Fapeg/CNPQ pelo financiamento da pesquisa.

\section{REFERÊNCIAS BIBLIOGRÁFICAS}

BERNARDINO, D. C. S.; PAIVA, H. N.; NEVES, J. C.; GOMES, J. M.; MARQUES, V. B. Crescimento e qualidade de mudas de Anadenanthera macrocarpa (Benth.) Brenan em resposta à saturação por bases do substrato. Revista Árvore, Viçosa, v. 29, n. 6, p.863870,2005 .

BRISSETTE, J. C. Summary of discussions about seedling quality. In: SOUTHERN NURSERY CONFERENCES, 1984, Alexandria, LA. Proceedings... New Orleans: USDA. Forest Service.Southern Forest Experiment Station, 1984. p. 127-128.

CALDEIRA, M. V. W., ROSA, G. N., FENILLI, T. A. B., HARBS, R. M. P. Composto orgânico na produção de mudas de aroeira-vermelha. Scientia Agraria, Curitiba, v. 9, n. 1, p.27-33, 2008.

CAIONE, G.; LANGE, A.; SCHONINGER, E. L.; Crescimento de mudas de Schizolobium amazonicum (Huber ex Ducke) em substrato fertilizado com nitrogênio, fósforo e potássio. Scientia Forestalis, Piracicaba, v. 40, n. 94, p.213-221, 2012.

CARVALHO, P. E. R. Espécies florestais brasileiras: recomendações silviculturais, potencialidades e uso da madeira. Brasília: EMBRAPA - CNPF/SPI, 1994. 640p.

CAVAlCANTE, A. L. G.; OlIVEIRA, F. A.; PEREIRA, K. T. O.; DANTAS, R. P.; OLIVEIRA, M. K. T.; CUNHA, R. C.; SOUZA, M. W. L. Desenvolvimento de mudas de mulungu fertirrigadas com diferentes soluções nutritivas. Floresta, Curitiba, v. 46, n. 1, p.47$55,2016$.

COSTA FILHO, R. T.; VALERI, S. V.; CRUZ, M. C. P. Calagem e adubação fosfatada no crescimento de mudas de mimosa Caesalpiniifolia benth. em latossolo vermelho-amarelo. Ciência Florestal, Santa Maria, v. 23, n. 1, p.89-98, 2013.

CRUZ, C. A. F.; PAIVA, H. N.; CUNHA; A. C. M. C. M.; NEVES, J. C. L. Macronutrientes na produção de mudas de canafístula em Argissolo Vermelho Amarelo da região da zona da mata, MG. Ciênc. Florestal, Santa Maria, v. 21, n. 3, p.445-457, 2011 a.

CRUZ, C. A. F.; CUNHA; A. C. M. C. M.; PAIVA, H. N.; NEVES, J. C. L. Efeito de macronutrientes sobre o crescimento e qualidade de mudas de canafístula cultivadas em latossolo vermelho-amarelo distrófico. Revista Árvore, Viçosa, v.35, n. 5, p.983-995, 2011 b. CRUZ, C. A. F.; PAIVA, H. N.; CUNHA, A. C. M. C. M.; NEVES, J. C. L. Produção de mudas de canafístula cultivadas em Latossolo vermelho amarelo álico em resposta a macronutrientes. Cerne, Lavras, v. 18, n. 1, p.87-98, 2012. 
DICKSON, A.; LEAF, A. L.; HOSNER, J. F. Quality appraisal of white spruce and white pine seedling stock in nurseries. Forestry Chronicle, Quebec, v. 36, n. 1, p.10-13, 1960.

DUTRA, T. R; MASSAD. M. D; SARMENTO M. F. Q; MATOS P. S; OLIVEIRA. J. C. de. Crescimento de mudas de umburana (Amburana cearensis) em resposta à adubação com nitrogênio e fósforo. Agropecuária Científica no Semiárido, Bahia, v. 11, n. 4, p.42-52, 2015.

EMPRESA BRASILEIRA DE PESQUISA AGROPECUÁRIA - EMBRAPA. Centro Nacional de Pesquisa de Solos. Manual de Métodos de Análise de Solo. Rio de Janeiro: Embrapa Solos, 1997. v. 1, 210 p.

FEITOSA, D. G.; MALTONI, K. L.; CASSIOLATO, A. M. R.; PAIANO, M. O. Crescimento de mudas de gonçalo-alves (Astronium fraxinifolium) sob diferentes fontes e doses de nitrogênio. Revista Árvore, Viçosa, v. 35, n.3. p.401-411, 2011.

FERNANDES, A. R.; PAIVA, H. N.; CARVALHO, J. G.; MIRANDA, J. R. P. Crescimento e absorção de nutrientes por mudas de freijó (Cordia goeldiana Huber) em função de doses de fósforo e de zinco. Revista Árvore, Viçosa, v. 31, n. 4, p.599-608, 2007.

FERREIRA, D. F. Sisvar: a computer statistical analysis system. Ciência e Agrotecnologia, Lavras, v. 35, n. 6, p.1039-1042, 2011.

FONSECA, É. P.; VALÉRI, S. V.; MIGLIORANZA, É.; FONSECA, N. A. N.; COUTO, L. Padrão de qualidade de mudas de Trema micrantha (L.) Blume, produzidas sob diferentes períodos de sombreamento. Revista Árvore, Viçosa, v. 26, n. 4, p.515-523, 2002.

FURTINI NETO, A. E.; SIQUEIRA, J. O.; CURI, N.; MOREIRA, F. M. S. Fertilização em reflorestamento com espécies nativas. In: GONÇALVES, J. L. M.; BENEDETTI, V. Nutrição e fertilização florestal. Piracicaba: IPEF, 2000. p. 352-379.

FURTINI NETO, A. E.; SIQUEIRA, J. O., CURI, N.; MOREIRA, F. M. S. Fertilização em reflorestamentos com espécies nativas. In: GONÇALVES, J. L. M.; BENEDETI, V. (Eds.). Nutrição e fertilização florestal. Piracicaba: IPEF, 2005. p. 351-384.

GOMES, J. M.; COUTO, L.; BORGES, R. C. G.; FONSECA, E. P. Efeitos de diferentes substratos na produção de mudas de Eucalyptus grandis W.Hill ex Maiden, em Win-Strip. Revista Árvore, Viçosa, v. 15, n. 1, p.35-41, 1991.

GOMES, J. M.; COUTO, L.; LEITE, H. G.; XAVIER, A.; GARCIA, S. L. R. Parâmetros morfológicos na avaliação da qualidade de mudas de Eucalyptus grandis. Revista Árvore, Viçosa, v. 26, n. 6, p.655-664, 2002.

GOMES, J. M.; PAIVA, H. N. Viveiros Florestais: propagação sexuada. Viçosa: UFV, 2011. $116 \mathrm{p}$.

GONÇALVES, J. L. M.; SANTARELLI, E. G.; MORAES NETO, S. P.; MANARA, M. P. Produção de mudas de espécies nativas: substratos, nutrição, sombreamento e fertilização. In:

Cultura Agronômica, Ilha Solteira, v.26, n.2, p.191-202, 2017 
GONÇALVES, J. L. M.; BENEDETTI, V. (Ed.). Nutrição e fertilização florestal. Piracicaba: IPEF, 2000. p. 309- 350.

GONÇALVES, J. L. M.; SANTELli, E. G.; MORAES NETO, S. P.; MANARA, M. P. Produção de mudas de espécies nativas: substrato, nutrição, sombreamento e fertilização. In: GONÇALVES, J. L. M.; BENEDETE, V. (Ed.). Nutrição e fertilização florestal. Piracicaba: Instituto de Pesquisas e Estudos Florestais, 2005. p. 352-383

MALAVOLTA, E.; VITTI, G.C.; OLIVEIRA, S.A. Avaliação do estado nutricional das plantas: princípios e aplicações. 2. ed. Piracicaba: Potafos, 1997. 319 p.

MALAVOLTA, E. Manual de nutrição mineral de plantas. São Paulo: Editora: CERES. 2006. $638 \mathrm{p}$.

MARENCO, R. A.; LOPES, N. F. Fisiologia vegetal: fotossíntese, respiração, relações hídricas e nutrição mineral. Viçosa: UFV, 2005. 451 p.

PAIVA, A. V.; POGGIANI, F.; GONCALVES, J. L. M.; FERRAZ, A. V. Crescimento de mudas de espécies arbóreas nativas, adubadas com diferentes doses de lodo de esgoto seco e com fertilização mineral. Scientia Forestalis, Piracicaba, v. 37, n. 84, p.499-511, 2009.

REIS, B. E.; PAIVA, H. N.; BARROSO, T. C.; FERREIRA, A. L.; CARDOSO, W. C. C. Crescimento e qualidade de mudas de jacarandá-da-bahia (Dalbergia nigra (Vell.) em resposta à adubação com potássio e enxofre. Ciência Florestal, Santa Maria, v. 22, n. 2, p.389-396, 2012.

RIBEIRO, M. M.; REISSMANN, C. B.; RESENDE, D. C. Nutrição da erva-mate com sulfato de amônio. Cerne, Lavras, v. 14, n. 3, p.204-211, 2008.

ROSSA, U. B.; ANGELO, A. C.; NOGUEIRA, A. C.; BOGNOLA, I. A.; POMIANOSKI, D. J. W.; SOARES, P. R. C.; BARROS, L. T. S. Fertilização de liberação lenta no crescimento de mudas de paricá em viveiro. Pesquisa Florestal Brasileira, Colombo, v. 33, n. 75, p.227234, 2013.

SANO, S, M.; RIBEIRO, J, F.; BRITO, M. A. Baru: Biologia e uso. Planaltina, DF: Embrapa Cerrado, 2004. 54 p. (Documentos, 116).

SANO, S. M.; BRITO, M. A.; RIBEIRO, J. F. Baru. In.: VIEIRA, R. F.; COSTA, T. da S.; SIIVA, D. B. da; FERRREIRA, F. R. ; SANO, S. M. (Ed.). Frutas nativas da região Centro - Oeste do Brasil. Brasília: Embrapa Recursos Genéticos, 2006. p. 76-99.

SANTOS, D.R.; GATIBONI, L.C.; KAMINSKI, J. Fatores que afetam a disponibilidade do fósforo e o manejo da adubação fosfatada em solos sob sistema plantio direto. Ciência Rural, Santa Maria, v. 38, n. 2, p.576-586, 2008.

SGARBI, F.; SILVEIRA, R. V. A.; HIGASHI, E. N.; PAULA, T. E.; MOREIRA, A.; RIBEIRO, F. A. Influência da aplicação de fertilizante de liberação controlada na produção de mudas de um clone de Eucalyptus urophylla. In: SIMPÓSIO SOBRE FERTILIZAÇÃO E

Cultura Agronômica, Ilha Solteira, v.26, n.2, p.191-202, 2017 
NUTRIÇÃO FLORESTAL, 2., 1999, Piracicaba. Anais... Piracicaba: IPEF-ESALQ, 1999. p. $120-125$.

SILVA, P. H. M.; STEIN, L. M. Produção de mudas e recomendações de adubação no viveiro para pequenos produtores. 2008. Disponível em: http://www.ipef.br/silvicultura/producaomudas.asp. Acesso em: 08 mar. 2016.

SILVA, P. M. C.; UCHÔA, S. C. P.; BARBOSA, J. B. F.; BASTOS, V. J.; ALVES, J. M. A.; FARIAS, L. C. Efeito do potássio e do calcário na qualidade de mudas de cedro doce (Bombacopsis quinata). Revista Agro@mbiente, Boa Vista, v. 7, n. 1, p.63-69, 2013.

SOUSA, D. M. G.; LOBATO, E. Cerrado: correção do solo e adubação. 2. ed. Brasília: Embrapa Informação Tecnológica, 2004. 416 p.

SOUSA, F. F.; VENTURIN, N.; CARLOS, L.; MACEDO, R. L. G.; LIMA, F. S.; SANTOS, S. C. Efeito de doses de nitrogênio e potássio sobre o crescimento de mudas de baru em casa de vegetação. In: CONGRESSO NACIONAL DE MEIO AMBIENTE DE POÇOS DE CALDAS, 12., 2015, Poços de Caldas. Anais..., v. 7, n. 1, Poços de Caldas: Instituto Federal do Sul de Minas, 2015. p. 1-8.

SOUSA, L. B.; NOBREGA, R. S. A.; LUSTOSA FILHO, J. F.; AMORIM, S. P. N.; FERREIRA, L.V.M.; NOBREGA, J.C.A. Cultivo de Sesbania virgata (Cav. Pers) em diferentes substratos. Revista de ciências agrárias /Amazonian Journal of Agricultural and Environmental Sciences, Amazônia, v. 58, n. 3, p.240-247, 2015.

SOUZA, C. A. M.; OLIVEIRA, R. B.; MARTINS FILHO, S.; SOUZA, J. L. S. Crescimento em campo de espécies florestais em diferentes condições de adubações. Ciência Florestal, Santa Maria, v. 16, n. 3, p.243-249, 2006.

TAIZ, L.; ZEIGER, E. Fisiologia vegetal. 3. ed. Porto Alegre: Artmed, 2004. 719 p.

TRAZZI, P. A. Substratos renováveis na produção de mudas de Tectona grandis Linn F. 2011. 84 f. Dissertação (Mestrado em Ciências Florestais) - Universidade Federal do Espírito Santo, Jerônimo Monteiro, 2011.

VIDAL, L. H. I.; SOUZA, J. R. P.; FONSECA, E. P.; BORDIN, I. Qualidade de mudas de guaco produzidas por estaquia em casca de arroz carbonizada com vermicomposto. Horticultura Brasileira, Brasília, v. 24, n. 1, p.26-30, 2006.

VIEIRA, C. R.; WEBER, O. L. S; SCARAMUZZA, J. F. Saturação por bases e doses de P no crescimento e nutrição de mudas de cerejeira (Amburana Acreana Ducke). Nativa, Sinop, v. 3, n. 1, p.01-09, 2015a.

VIEIRA, R.; WEBER, O. L. S. Influência do substrato na produção de mudas de espécies medicinais. Nativa, Sinop, v. 3, n. 2, p.135-142, 2015 b.

XAVIER, A.; WENDLING, I.; SILVA, R. L. Silvicultura clonal: princípios e técnicas. Viçosa, MG: UFV, 2009. 272 p.

Cultura Agronômica, Ilha Solteira, v.26, n.2, p.191-202, 2017 